\title{
On Searle and the collapse of civilization
}

Rodrigo González-Fernández (rodgonfer@gmail.com) Facultad de Filosofía y Humanidades, Universidad de Chile (Santiago, Chile) https://orcid.org/0000-0001-9693-0541

\begin{abstract}
This article addresses a neglected problem in Searle's social ontology, namely, how human civilization may collapse. In the first section, I provide the theoretical framework. In the second section, I offer the key elements to understanding Searle's ontology as well as his philosophy of society, emphasizing the role of constitutive rules and deontic powers. In the third section I examine how they improve trust and co-operation. Global and local natural disasters are distinguished in the fourth section, because the former is sufficient to undermine pacts, promises, constitutive rules and deontic powers, while the latter is neither sufficient nor necessary. In the fifth and final section, I put forward an argument via a thought experiment that allows us to anticipate what would occur if people did not keep promises and pacts, on the one hand, and did not respect constitutive rules and deontic powers, on the other hand. Such events, I argue, would result in the collapse of civilization.
\end{abstract}

Key words: Searle, ontology, civilization, trust, co-operation, collapse.

\section{Introduction}

Searle has proposed a theory that explains the structure of human civilization, as we know it. It is worth mentioning that Searle's view counts as a philosophical system, an extraordinary philosophical feat. Mind, language, and society are explained by applying synthesis, that is, by relating them together so that they can explain reality. For example, mind is fundamental for his view, because consciousness, which involves sentience, and intentionality, which involves representation via intentional mental states, have fundamental roles in how we deal with the social world. Language, with illocutionary acts, is also important, as certain speech acts such as promises, and declarations elucidate the normative features of social reality. Finally, Searle has provided logico-philosophical tools that explain this reality, making all the connections with mind and language.

While Social Ontology is essential for the explanation of the social world, and especially for the account of how human civilization has arisen, it is not entirely clear how the social world may collapse, at least according to Searle's view. That is, he has provided an analysis of the making of human civilization; even so, it remains an open question how human civilization may turn out to be un-made. In relation to this point, Searle himself has only sketched the circumstances under which a society is in crisis; for example, he asserts the following in relation to institutional structures and people: "It is tempting to think that such institutional structures as property and the state itself are maintained by the armed police and military power of the state, and that acceptance will be compelled where necessary. But in the United States, and in several other democratic societies, it is the other way around. The armed might of the state depends on the acceptance of systems of 
constitutive rules, much more than conversely. This was apparent at the time of the well-televised street riots in Los Angeles in 1992. Looters walked out of the stores carrying valuable property while the police pointed their guns at them and ordered them to stop. The looters simply ignored the police, with no further consequences" (Searle 1995:90, my emphasis).

In this essay, I go a step further that Searle by addressing the problem of civilization collapse, i.e., by explaining how certain conditions must be satisfied for its collapse, at least in Searlean terms. Take, for example, global warming, climate change, a pandemic, etc.: some people may think that all these contribute to the civilization collapse. The hypothesis that I will formulate considers the role that pacts, promises, status functions, constitutive rules and deontic powers play in the making of the social world. Against this background, I hypothesize what would occur if, for example, a global natural disaster occurred without destroying the Earth. Insofar as the consequences of the disaster had permanent effects, would people cease keeping their promises and solemn pacts? Would they simply ignore constitutive rules and deontic powers? I precisely attempt to respond to these questions.

The essay is divided into five sections and a conclusion. In the first section, I introduce the reader to the issues I deal with. The second section provides the key elements of Searle's Social Ontology, so that the reader has the appropriate context to grasp the thought experiment about the civilization collapse. In the third section, I characterize the role that constitutive rules and deontic powers play in the making of the social world. Dealing with natural disasters, I distinguish between global and local disasters in the fourth section. While the former can bring about the civilization collapse due to permanent effects, the latter do not. In the fifth and final section, I introduce an alternative thought experiment from which I conclude that, if people did not keep promises and solemn pacts, and did not respect constitutive rules and deontic powers, institutions would simply disappear. In the conclusion, then, I systematize the consequences of the alternative thought experiment; specifically, I show how a radical change of the relevant mental states and attitudes, of those necessary to maintain institutions, may bring about the civilization collapse. Or, in other words, the conditions described by the new thought experiment evince how the social world could be un-made.

\section{The $A B C$ of social ontology}

As Searle holds, "we live in one world" (Searle 2010:3). In this world, particles, and organized systems of particles in fields of force exist. There are neither two nor three worlds: nature vs culture or nature, culture and society. On the contrary, the world described by physics and chemistry is the only world that exists. Searle then puts forward the following thesis: there is just one world, and this one world is mostly described by two sciences, i.e., physics and chemistry. As is evident, this thesis is quite strong, so that the following questions arise: what is the role of social sciences, and what do such sciences elucidate? The thesis, though, has an important addendum: in the world of physical particles, there are systems that have evolved to the point of developing two biological features of the human brain and the nervous system: consciousness and intentionality. On the one hand, consciousness is essential for sentience; on the other hand, intentionality is crucial for the cognition of things that merely exist in virtue of our intentional mental states, that is, for things that depend upon how we represent them.

Searle's ontology distinguishes between brute facts and institutional facts. Brute facts do not depend upon any observer or observation (for example, the mass of the moon), because they are 
intrinsic properties of objects, while institutional facts do depend upon the existence of observers (for example, marriage), because they only exist if we believe that they exist. This distinction does not involve dualism (again, nature vs culture), but a difference between things that depend upon observers, and others that do not. If all human observers, or all sentient beings disappeared, intrinsic features of the world, would not disappear; in contrast, institutional facts, which are observerdependent would all disappear at once. That is, marriage, money, presidents, parliaments, cocktail parties, wars, and an endless list of institutional facts would cease to exist, if humans disappeared. I will return to this thought experiment in the fourth section of this essay.

One feature of the biological organisms that have developed consciousness and intentionality is that they co-operate. Besides individual intentionality, which explains beliefs, and desires as well as other mental states that evince aboutness, human beings co-operate to pursue and attain goals that are impossible to further without co-operation. For example, it would be impossible to play music in an orchestra, if certain persons did not trust and co-operate to achieve this goal. By the same token, it would not be possible to purchase goods if we, human beings, did not collectively believe that money serves as a basis for economic transactions (I return to this point below).

What goes for the orchestra and money can be generalized to all kind of facts that depend upon institutions. According to Searle, these are systems of constitutive rules which reflect collective intentionality, that is, of people's capacity of acting together co-operating. One necessary condition of collective intentionality is of course co-operation, because only coordinated behaviour exists otherwise. A necessary condition for co-operation is the understanding of others as cognitive agents. In fact, most animals only show coordinated behaviour, because they do not explicitly cooperate to achieve goals as humans do with collective intentionality. Human beings, in other words, see other people as intentional agents. Moreover, humans act in view of goals that can be pursued collectively, and even politically: we play football, we play music orchestral music, we play chess, we debate political ideas, and so on. Emphasizing the role of co-operation in collective intentionality, Searle offers the examples of Business School case 1 and 2:

"BUSINESS SCHOOL CASE 1. Imagine a group of Harvard Business School graduates who were taught and come to believe Adam Smith's theory of the invisible hand [...] After graduation day, each goes out in the world and try to benefit humanity by being as selfish as each of them possibly can and by trying to become as individually rich as they can [...]

BUSINESS SCHOOL CASE 2. There is a second possible case where we imagine they all get together on graduation day and make a solemn pact that they will go out and try to help humanity by becoming as rich as they can and by acting as selfishly as they can [...]

There is a tremendous difference in the two cases because in the second case there is an obligation assumed by each individual member. In the first case, the individuals have no pact or promise to act in this way [...] But in the second case, there is a solemn promise made by each to all the others" (Searle 2010:47, my emphasis).

Now, in view of collective intentionality an amazing thing occurs according to Searle's ontology, which explains the creation of the social world, namely, we can attribute functions to objects which would not have them only in virtue of their physical properties. For example, a piece of coloured paper with signs, numbers and representations acquires meaning in virtue of our assignment of 
function, i.e., it is one dollar, a token of money. And, given Searle's Social Ontology, money plays a fundamental role in society: it is an institution that we trust, because it serves all kinds of economic transactions. Were it not for money, we would need to exchange goods in a far more complicated way, and economic values would be far less clear. What is amazing about money, qua institution, is that functions are assigned by us collectively, according to the following formula: $X$ counts as $Y$ in $C$. In other words, $X$, a piece of paper, counts as $Y$, one dollar, in the US. As a result, collective intentionality and the assignment of functions are two necessary conditions for the existence of institutions.

Constitutive rules enable certain social activities, which would not exist otherwise. Searle uses the typical example of chess. Unlike driving on the right side of the road, which counts as a regulative rule that pre-govern movements, chess involves rules that need to be followed to create the very existence of the game. Additionally, collective intentionality, status functions and constitutive rules need an element that is not present in the animal kingdom, namely, language. Linguistic signs are necessary, but not sufficient for the creation of institutions that are the product of collective intentionality, status functions and constitutive rules. Institutions must be declared as such, and this occurs because certain speech acts, that is, declarations, play a key role in the creation and maintenance of institutional facts. He is emphatic on this point: "You can have a society that has language but does not have governments, private property, or money. But you cannot have a society that has governments, private property, and money, but does not have a language. I think everyone would agree to this, but the important philosophical task is to say exactly why it is true. All human social institutions are brought into existence and continue their existence by a single logico-linguistic operation that can be applied over and over again [...] There is a top-down connection between language and institutional facts: you cannot have institutional facts without language. And once you have a shared language you can create institutional facts at will" (Searle 2010:62).

Institutions, by which social practices in a human society are grounded, are co-extensive with constitutive rules and deontic powers. Money, for example, synthesizes how people buy, sell, and rent certain goods. Marriage synthesizes how people commit themselves to being couples in a community. A parliament synthesizes how political ideas are to be debated by politicians so that laws are passed. Thus, institutions are the key factor that explains the creation of civilization and how it continues existing, because civilization would not exist, if institutions did not exist either. Accordingly, human institutions summarize how certain social practices come into existence, and how they are maintained over time in terms of the followed constitutive rules, and in terms of how deontic powers are respected.

However, institutions show another special feature, which is essential to any understanding of the social world: they involve self-referential social concepts. That is, general social concepts about institutions refer to themselves as they need to be seen, believed, or used to exist. From a logical viewpoint, for instance, " $X$ is money" implies an undefined disjunction like the following: " $X$ is seen as money", or " $X$ is believed as money", or " $X$ is used as money" (Searle 1995:32). Thus, the definition of money is self-referential because, in order that $X$ satisfies the definition, $X$ must be seen, believed, or used as money. Notice that the same applies to all institutions. From Searle's analysis, it follows that, if an institution is not used, believed, or seen as money, this very institution disappears from the social world. This process may affect, in fact, all institutions, a problem that is central to the forthcoming sections. 


\section{Constitutive rules, deontic powers, and trust: the virtuous circle}

The rise of human civilization is explained in society by: i) how collective intentionality requires a solemn pact, and ii) the role that constitutive rules and deontic powers play. Take the simple example of buying a soft drink. Suppose that there is a nearby convenience store that sells soft drinks and food. Imagine, then, that a buyer, Mary, believes that her bill counts as money in the US. On the other hand, imagine that the seller, John, believes that soft drinks can be purchased with tokens of money, that is, with dollar bills. Both Mary and John are prone to trusting each other, as both take for granted that a simple operation such as buying a soda only requires the following things: the existence of money, the meaning of money, and the mutual sincere will of them as buyer and seller respectively.

Hyperbolic doubts are rather scarce in the social world, although sometimes they manage to exist in certain contexts, the mafia, for example. Trust, in turn, is what usually makes agents respect solemn pacts and promises, giving rise to co-operation at all levels. In fact, in daily life, Cartesian evil demon scenarios are practically inexistent, and/or irrelevant. A world in which there is no trust is a world with forms of paranoid cognition. Unlike trust, doubt and radical distrust are not social lubricants since neither favour rational actions in the social reality.

Nevertheless, it is crucial to emphasize how trust counts as "a social lubricant" (Yamagishi 1998:17), because it indeed favours co-operation and an enriched social life. As Luhmann points out, trust renders simpler the complexity of the future thus: "We are now in a position to formulate the problem of trust as a gamble, a risky investment. The world is being dissipated into an uncontrollable complexity; so much so that at any given time people are able to choose freely between very different actions. Nevertheless, I have to act here and now [...] If I can trust in sharing the proceeds, I can allow myself in forms of co-operation which do not pay off immediately and which are not directly visible as beneficial [...] Trust is not only involved when the trusting expectation makes a difference to a decision; otherwise what we have is a simple hope" (Luhmann 2009:24, my emphasis).

Even though Searle has not noted the role of trust in the social world, constitutive rules and deontic powers are fundamental to strengthen it. We co-operate when we follow the constitutive rules that create and make possible certain social practices, such as buying a soft drink. When we proceed with the transaction, we act in accordance with the rules of buying and purchasing. Similarly, deontic powers that are associated with specific roles in society, such as being a police constable, a teacher, a president, and others, also strengthen trust. Respecting those deontic powers provide desireindependent reasons for action, and in virtue of these, people expect from police constables, teachers, and presidents to act as they are supposed to. People simply trust them, because, as part of certain institutions, they ought to act according to desire-independent reasons for action, i.e., by postponing their immediate desires.

Most people trust that those who belong to an institution will: i) keep solemn pacts and promises, and ii) act in accordance with their constitutive rules and deontic powers. That is, people trust that those who belong to an institution will act considering certain desire-independent reasons for action. Thus, constitutive rules plus deontic powers strengthen trust because they make the future less complex, especially from the point of view of social relations. But is trust strengthened by 
constitutive rules and deontic powers, or are constitutive rules and deontic powers strengthened by trust?

The soft drink example is clear enough to conclude that constitutive rules and deontic powers strengthen trust. But we may hold the opposite too. An example will serve to clarify in what sense trust strengthens constitutive rules and deontic powers, showing a virtuous circle. Suppose a surgery team is saving Bill's life: in such a case, surgeons follow a prescribed procedure governed by constitutive rules. Now, Bill's relatives trust the surgery team. Hence, the deontic powers that enable the team to save Bill are fundamental. The family trust that the doctors and nurses will act as they are supposed to, and the nurses trust the doctors in view of the deontic powers involved. In Bill's case, trust in the constitutive rules and deontic powers favours the social procedures to save him, and this evinces a virtuous circle: constitutive rules and deontic powers strengthen trust, but occasionally trust also strengthens such rules and powers. As Krause and González emphasize emphasizes: "In the social world, we tend to trust, because trusting is a way to deal with the complexity of the future. For example, it would be improper to distrust the surgeon that operates someone, as a conspiracy philosopher could eventually favor. In that context, hyperbolic doubts would be counterproductive, as they may obstruct the surgical procedure itself. [...] Trusting here involves that those members of the surgical team are committed to satisfying a set of rules related to a complex action; in this case, a medical procedure" (Krause and González 2016:47).

Despite the suspicious attitude of low trusters, people make and keep promises most of the time. We, like the high trusters, trust other people and expect that they will behave according to certain constitutive rules and deontic powers (see, for example, the third paradox of trust in Yamagishi, who claims that it is a myth that high trusters are gullible and naïve). As a result, while low trusters mostly distrust other people, guessing hidden motives for action, high trusters are more sensitive, attentive or cautious about the potential social risks, given the information of potential trustworthiness or the lack of it in other people.

Another element of the virtuous circle is the role of status indicators in Searle's Social Ontology. For example, a police constable has a uniform and a badge that identifies her as such. Further, the uniform causes other persons to identify a police constable correctly. Were it not for those signs, which operate as linguistic signs, it would be difficult to distinguish a police constable from a simple person. What is amazing about the police is that we trust them as we suppose that they will act according to certain constitutive rules and deontic powers. Moreover, those linguistic signs make us presuppose that the police will act as they are supposed to act, that is, enforcing the law. These presuppositions are indeed part of the background of pre intentional abilities that enable us to correctly deal with the social world.

Status indicators, qua linguistic signs, in many cases make people trust almost automatically. Given the background of pre-intentional abilities, we automatize the identification of police officers to the extent that we do not need to consciously assume that police constables are the police. Rather, we simply assume that the police are here because we automatically assume that their uniforms and badges tell us that they are the police. In fact, this is the reason why criminals sometimes wear fake police uniforms: their aim is to be misidentified as the police. Furthermore, in most cases criminals want to be trusted as though they were the police. In the case of fake police uniforms, we fail to identify the true police constable, and this make us trust the wrong person almost automatically. 
Asides from criminals and impostors who wear fake uniforms, there are other events which make us fail to act in accordance with certain constitutive rules and deontic powers. The next section deals with some peculiar events that lead people to respect neither constitutive rules, nor deontic powers, namely, natural disasters. In addition, in such extraordinary circumstances people may stop keeping promises and solemn pacts. Two kinds of disasters must be distinguished: local and global natural disasters, as the third section examines.

\section{Natural disasters: local and global}

A disaster is defined as a sudden accident or a natural catastrophe that causes great damage or loss of life. In turn, natural disasters are defined as major adverse events resulting from the natural processes of Earth. Natural disasters are therefore natural hazards that threaten lives and livelihoods, and this can be seen by the way in which our daily life scenarios dramatically change. For example, it is common that people disregard all the social events that take place during and after a natural disaster. Furthermore, our own lives can be at risk because of the impact of natural disasters or health emergencies. Indeed, people die owing to the effects of natural disasters and health emergencies. Consequently, the former and the latter can change the way in which we experience daily life, and the sense in which we experience time. For this reason, both natural disasters and health emergencies require specific policies aimed at the management of the risks involved.

Although it seems obvious that natural disasters can dramatically change our lives in many different senses, it is not clear how they do it in view of Searle's Social Ontology. In this section, I will not attempt to clarify how natural disasters require risk management and specific policies; rather, I clarify how such disasters may cause people disregard: i) promises and solemn pacts, and ii) constitutive rules and deontic powers, to the extent that collective intentionality is ultimately affected. It is clear that natural disasters belong to the physical world, and for that reason, they count as brute facts rather than institutional facts (e.g. an earthquake versus its declaration as a catastrophe). But the question that remains open is whether brute facts can affect the existence of the seen, believed, or used institutions.

My hypothesis is that natural disasters can imply an important challenge to the social world, since they can dramatically change the way observers see, believe, or use observer-dependent phenomena. In other words, my claim is that natural disasters are physical events and processes of nature, which not only affect the physical world. Additionally, they test the solidity of the social world. It is thinkable, at least, that a major natural disaster may cause the collapse of human civilization, although it is trivial that a major natural disaster may cause the civilization collapse, since the whole world could well disappear. A caveat is therefore necessary here: the analysis I favour considers that those disasters, both natural disasters and health emergencies, put the social world at risk, but without making the world disappear from a physical viewpoint. Thus, I only concentrate here upon those disasters that are sufficient to impact the way we see, believe, or use institutions.

Now, a wide range of natural disasters put the social world at risk, without destroying the whole planet. Earthquakes, volcano eruptions, tornados, hurricanes, floods, droughts, pandemics, etc. seem to be able to put at risk the existence of the social world. Although there is a long list of natural disasters, it is important to distinguish between local and global natural disasters. Whereas the 
former put a restricted social group at risk, the latter serves as a threat to the whole of humanity. A meteorite hitting the Earth, for example, can make humans disappear, and as such counts as a global natural disaster. In contrast, an earthquake usually affects a specific geographic area, and as such counts as a local natural disaster. This distinction is quite important, since the whole of humanity is not necessarily at risk when natural disasters occur (I will return to this point below). As a result, and for the sake of argument, I mainly focus upon global natural disasters that involve major changes in the way people see, use, or believe in institutions.

A few examples of local natural disasters can illustrate the point I intend to stress here: they can dramatically change our lives in the social world, as, again, they change the way institutions are seen, believed, or used.

Local natural disasters cause great economic damage, plus the loss of lives. For example, according to statistics, hurricane Katrina caused 81 billion dollars in economic damages (Ewing, Kruse, Sutter. An overview of hurricane Katrina and economic loss). Hitting Louisiana, Florida, Texas, and Mississippi, the hurricane caused a high rate of unemployment for several months. Many companies filed for bankruptcy, following the hurricane. For that reason, Katrina, which is considered the costliest natural disaster in US history, showed how a physical catastrophe can dramatically affect the social world, i.e., how a sudden change in brute facts can dramatically impact institutional facts. This event of nature also shows that Searle's thesis about the one shared world is in some sense correct: "Hurricane Katrina" implies an event having great impact on the social world. Therefore, upon the basis of local natural disasters it is possible to conclude that a continuum between the physical world and the social world exists.

However, it is important to bear in mind that a local natural disaster does not necessarily imply the collapse of human society. Take, for example, what occurred in the 2011 earthquake and tsunami in Japan, which did not affect: i) how people kept their promises and solemn pacts, and ii) how the constitutive rules and deontic powers of that society were respected. In fact, Japanese people who were affected by the earthquake and tsunami did not stop believing in institutions such as the police and the military forces; on the contrary, Japanese people showed great respect for those institutions, as they showed the continued existence of the Japanese society. Thus, a local natural disaster may cause a crisis in collective intentionality, but that is not necessary; moreover, a local natural disaster may not cause a dramatic change in collective intentionality, as a global natural disaster does. In view of the 2011 earthquake and tsunami in Japan, it is possible to conclude that a local natural disaster is neither sufficient nor necessary for the collapse of the social world.

Nevertheless, other natural disasters, such as the 2010 earthquake and tsunami in Chile showed us that the impact on the social world can: i) make people disregard promises and solemn pacts, and ii) undermine constitutive rules and deontic powers, at least momentarily, causing great economic damage. Although the 2010 earthquake and tsunami in Chile can be regarded as a local natural disaster, it caused great havoc on Chilean society. The 2010 earthquake, which occurred off the coast of Central Chile, on 27 February 2010, had a magnitude of 8.8 on the Richter scale. Causing intense shaking for three minutes, the earthquake, which was felt in six Chilean regions (from Valparaiso to Araucania), affected almost $80 \%$ of the Chilean population. Furthermore, after the earthquake and tsunami, looting in towns and cities lasted for several days and nights. 
In fact, the 2010 earthquake in Chile caused a blackout that affected 93 percent of the country, and President Michelle Bachelet had to declare a "state of catastrophe," which meant that military troops had to take control of the cities Concepcion and Talcahuano, badly hit by the earthquake. Declaring the state of catastrophe was necessary because the looting was intense in those cities. What is interesting about such looting, though, was that those people who did not keep the solemn pacts and promises, stopped believing in constitutive rules, especially in those related to institutions, both private and public. Furthermore, certain people stopped believing in the power of the state, and started behaving like the mafia, that is, with excessive rationalistic individualism, widespread distrust, all of which causes violence and collective disaster.

The earthquakes and tsunamis in Chile and Japan had different social effects, although the brute facts involved were similar. Nevertheless, it is interesting in this analysis that the Chilean and Japanese people had similar constitutive rules and deontic powers, but the way institutions were seen, believed, and used were quite different. This may be explained by the fact that collective intentionality is crucial to the appraisal of social institutions. But in what sense does collective intentionality plays a central role in the appraisal of institutions? Despite the arguments offered by Yamigishi, it seems that trust and cooperation are stronger in the Japanese society, and this difference meant a significant difference for the way people see, believe, or use Japanese institutions.

What occurred with the 2010 earthquake and tsunami in Chile may lead us to anticipate the kinds of social events that might take place in the event, of global natural disaster. Again, the question is not one of the wholesale devastations, but rather of socially contextual disaster. In such a case, it seems that collective intentionality would be dramatically affected, and some people would choose to neither follow constitutive rules, nor respect deontic powers, thus leading to social dissension and disunity, all of which encourage forms of distrust. In the next section, I analyse such possibilities using a thought experiment.

\section{A thought experiment on the collapse of human civilization}

We can anticipate what the collapse of civilization might be like, especially in view of Searle's Social Ontology. We can examine what kind of social impact a global natural disaster might have on humanity, and what kind of social consequences might ensue. Clearly, we do not have to wait for a local natural disaster to study the economic losses that cause great damage to an economy. For example, we may simulate what might occur if another hurricane such as Katrina hit the US east coast, foreseeing the consequences. Similarly, we do not have to wait for a global natural disaster to estimate what would occur if, for example, a meteorite hit the Earth and did not destroy it completely. On the contrary, and in view of Searle's Social Ontology, we may imagine what would be the case if the meteorite were to hit the Earth, profoundly affecting the social world. The economic losses could indeed be predictable; however, for the purposes of this essay, our aim will be to anticipate how the social world might radically change, especially regarding trust, cooperation, and collective intentionality.

Searle performs a thought experiment to distinguish between observer-independent and observerdependent features of the world. In relation to this idea, he stresses the importance of humanity and observers thus: "A good rough-and-ready way of getting at this distinction [observer-relative and non-observer relative features of the world] is to ask yourself: Could the feature exist if there 
had never been any human beings or other sorts of sentient beings? Observer-relative features exist only relative to the attitudes of observers. Intrinsic features don't give a damn about observers and exist independently of observers [...] Intrinsic features of reality are those that exist independently of all mental states, except for mental states themselves, which are also intrinsic features of reality" (Searle 1995:11).

This view supports a simple and straightforward thought experiment. The thought experiment is as follows:

(i) Observer-dependent facts exist only if observers exist

(ii) Institutional (as opposed to brute) facts are kinds of observer-dependent facts

(iii) Suppose that observers did not exist

Then, if follows that institutional facts would not exist

Notice that certain changes in nature may lead to a significant impact on the social world. Although it is trivial that brains and nervous systems are part of the natural world, and that they can be destroyed causing mental states to disappear, it is not trivial that a global natural disaster might have an impact on the whole civilization. In other words, it seems obvious that if nature disappears, we will disappear too. But it is not obvious what would occur if a global natural disaster substantially modified nature without destroying it. This is precisely the point I intend to emphasize in relation to global natural disasters: they do not necessarily imply the disappearance of nature; still, they may have a substantial impact on the appraisal of human institutions. But, in what way a global natural disaster affects the social world?

As I see it, Searle's original thought experiment can be modified, giving rise to an alternative thought experiment. For we might maintain the existence of humanity constant, and yet imagine that a disaster radically changes how institutions are seen, believed, or used by humans. The intuition that would arise is this: a global natural disaster may change nature to the extent that a large number of mental states are modified, by pacts and promises not being kept, and by constitutive rules and deontic powers not being respected. A state of catastrophe can affect promises to the degree that they need not be respected anymore. For example, if Bill is hungry because he has not eaten for 4 days, it is likely that he will disregard the institution of private property. In fact, Bill may behave like a member of the mafia, in the sense that he could engender excessive individualism and distrust.

Notice that it would not be the case that the global natural disaster itself would necessarily cause the civilization collapse. Rather, it could be the case that such a disaster might affect people, for a long or short period of time, by making them not keep promises, and not believe in constitutive rules and deontic powers permanently. Bill's state of hunger may affect how institutions are seen, believed, or used by him. Again, Bill may start disregarding the power of the state, like a member of the mafia, and may engender individualism and distrust. Consequently, the civilization collapse would not be a brute fact, but a product of the collapse of collective intentionality, constitutive rules, and deontic powers.

Based upon the alternative thought experiment, the argument I put forward in this section is as follows: 
(i) Constitutive rules and deontic powers are essential to the existence and maintenance of human civilization.

(ii) Certain global natural disasters can potentially undermine constitutive rules and deontic powers, even affecting solemn pacts and promises.

Therefore, certain global natural disasters can potentially lead to the collapse of human civilization.

Notice further that a local natural disaster is neither necessary nor sufficient for human civilization collapse. This follows from the 2010 earthquake and tsunami in Chile, and 2011 earthquake and tsunami in Japan. The uprising of violence and looting in Chile was not permanent. Even though Japan was hit by a local natural disaster, Japanese people did not stop believing in promises, pacts, constitutive rules, and deontic powers. On the contrary, and as remarked above, the Japanese people continued believing in their constitutive rules, their deontic powers, and most importantly, in the collective intentionality that is necessary for the appraisal of institutions. From this, we can conclude that a local natural disaster may have an impact on the social world, but such an impact will not necessarily be sufficient to result in the social world collapse.

In contrast, certain global natural disasters can be sufficient for the collapse of civilization, especially if the dramatic changes they involve are permanent. Again, this is important, since as seen, there was a notable difference between the social response to the 2010 earthquake and tsunami, and the 2011 earthquake and tsunami. Only the former, which is more like a global natural disaster, put important cities on the verge of social chaos, unlike what occurred with the Japanese people, who maintained belief in their institutions. Thus, we are led to the following conclusion: not respecting constitutive rules and deontic powers, and not keeping pacts and promises, with the subsequent crisis of collective intentionality, can have an impact on the social world, causing chaos, which may lead to the collapse of institutions and, thus, of human civilization.

\section{Conclusion}

In this essay, I explored the under examined question of how to understand the conditions under which civilization could come apart using the tools of Searlean analytics. In particular, I focused on the case of natural disasters, because I am interested in the continuity that holds between the natural and social world, and how the one can affect the other in the question not of social construction but social deconstruction/collapse. Concepts such as status functions, constitutive rules, deontic powers, promises, and solemn pacts have been examined, so that the reader grasps in what sense human civilization exists and is maintained. Nevertheless, these concepts have also shown what factors may trigger a deep crisis of the civilization. Amongst those factors, I have underlined how certain natural disasters may cause a crisis by making people disregard promises and pacts and neglect constitutive rules and deontic powers.

For the sake of argument, I have distinguished between local and global natural disasters. Some local natural disasters may make people disregard institutions for a short period of time. By contrast, some global natural disasters can be sufficient for undermining constitutive rules, deontic powers, pacts, and promises. Indeed, such disasters may affect the self-referentiality of social institutions, and thus how institutions are seen, believed, or used by observers. A variation of a Searlean thought experiment has been examined to endorse this view. Modifying Searle's thought experiment, we 
may in turn ask: if we imagined that nature changed due to a global natural disaster, what consequences would follow for human civilization?

The intuition that follows this new thought experiment is that, if constitutive rules and deontic powers were neither followed nor respected, and pacts and promises were not kept, institutions, which are self-referential, would simply disappear. This would occur because the social world is mind-dependent, and our commitments and pacts, which are crucial for what we see, believe or use, may cease to exist. In effect, collective intentionality would be affected as follows: not keeping pacts and promises would lead to an excess of individualism, and to dissension and disunity, all of which are perils for the existence and maintenance of institutions.

Human civilization exists because we keep promises and commit ourselves to respecting constitutive rules and deontic powers. But a major crisis triggered by a global natural disaster may dramatically change this scenario for a relevant period. If this dramatic scenario occurred, the following question might arise: Would human civilization collapse? A trivial answer to this question is to say: when observers and their minds did not exist anymore.

However, another way to deal with the question in a non-trivial way is the following: human civilization may collapse if we stop believing in what constitutes the civilization itself, that is, what involves the making of human civilization. If pacts, promises, constitutive rules and deontic powers were undermined, collective intentionality might simply disappear, and human civilization might also collapse. For this reason, I have concentrated upon those conditions that would be sufficient for making human civilization collapse due to the crisis of collective intentionality, constitutive rules, and deontic powers.

Notice that such conditions can be satisfied if nature radically changed due to global warming, a pandemic, a meteorite, etc. However, those conditions would need to be sufficient for the undermining of pacts, promises, constitutive rules and deontic powers. In short, a moral can be drawn from analysing Searle's ontology and the eventual collapse of human civilization: even though human civilization is fragile, since promises, pacts, constitutive rules and deontic powers are all mind-dependent, it has been strong enough to allow humans to live in the Serlean world, that is, in the only world that we share.

\section{References}

Krause, M.S; González, R. (2016) La confianza en la construcción de la realidad social. Revista de Filosofía 4(1), 33-53. https://doi.org/10.5209/rev RESF.2016.v41.n1.52106

Luhmann, N. (2009). Trust and power. Wiley.

Searle, J. (1995). The construction of social reality. The Free Press.

Searle, J. (2010). Making the social world: the structure of human civilization. Open University Press.

Yamagishi, T. (1998). The structure of trust: an evolutionary game of mind and society. Tokyo University Press.

Received 15 Ago 2020

Accepted 26 Oct 2020 